\title{
O ALUNO EM FOCO - UM PANORAMA SOBRE A PRODUÇÃO AUDIOVISUAL DE DOCUMENTÁRIOS POR ESTUDANTES EM CONTEXTO ESCOLAR
}

\author{
THE STUDENT IN FOCUS - AN OVERVIEW OF AUDIOVISUAL PRODUCTION OF \\ DOCUMENTARIES BY STUDENTS IN A SCHOOL CONTEXT
}

\author{
(iD) Andrea Cristina Versuti \\ Doutora em Educação, Ciência e Tecnologia \\ Universidade de Brasília -UnB \\ Brasília, DF - Brasil \\ andreaversuti@unb.br \\ Érico Monnerat \\ Mestrando em Educação: Educação, Tecnologias e Comunicação \\ Universidade de Brasília -UnB \\ Brasília, DF - Brasil \\ ericomonnerat2@gmail.com
}

Resumo: O presente artigo apresenta uma revisão bibliográfica sistemática nas plataformas Capes, Eric e Scielo das pesquisas sobre produção audiovisual do gênero documentário com alunos e ênfase na autoria, protagonismo e autonomia dos estudantes durante a realização das obras. O artigo contextualiza, também, a importância de tais práticas a partir das competências gerais da Base Nacional Comum Curricular, da relevância do multiletramento (ROJO, 2009) e aponta para a potência de novas pesquisas sobre a produção de imagens no âmbito da convergência digital, da cultura participativa (JENKINS, 2009) e do estado de ubiquidades dos aparelhos (SANTAELLA, 2014) em sala de aula.

Palavras-chave: educação; documentário; produção; autonomia; protagonismo.

Abstract: The article presents the systematic literature reviewof research on audiovisual production of the documentary genre with students and emphasis on the authorship, protagonism and autonomy of the students during the execution of the works in repositories Capes, ERIC and Scielo, It also contextualizes the importance of such practices from the general competences of the Common National Curriculum Base, the relevance of digital multiliteracy (ROJO, 2009) and points to the power of new research on the production of images in the context of digital convergence and participatory culture (JENKINS, 2009) and the state of ubiquity of devices (SANTAELLA, 2014) in the classroom.

Keywords: education; documentary; production; autonomy; protagonism.

Para citar - ABNT NBR 6023:2018

VERSUTI, Andrea Cristina; MONNERAT, Érico. O aluno em foco - um panorama sobre a produção audiovisual de documentários por estudantes em contexto escolar. Cadernos de Pós-graduação, São Paulo, v. 20, n. 1, p. 189-205, jan./jun. 2021. Disponível em: https://doi.org/10.5585/cpg.v20n1.19682. 


\section{Introdução}

Uma visão panorâmica

Um dos maiores e mais importantes desafios da educação de nosso tempo é a construção de um uma escola mais humana e conectada às vivências e subjetividades dos alunos. Desafio dobrado pelo momento em que a velocidade das tecnologias e da sociedade demanda uma adequação ao novo, ao mercado de trabalho, em um ritmo que descompassa o que temos dentro e fora dos muros da escola (SIBILIA, 2012). Entre estas tecnologias que pressionam as práticas pedagógicas sem pedir licença, mudando o espaço de aprendizagem e as relações pessoais damos destaque neste artigo ao audiovisual. Presente em aparelhos cada vez mais ubíquos (SANTAELLA, 2014) ele traz consigo um caráter dual, ao permitir uma conexão permanente com o mundo externo, por meio das telas, ao mesmo tempo em que entrega uma ferramenta poderosa de reflexão - a câmera.

Este artigo busca, por meio da revisão bibliográfica sistemática (WEBSTER e WATSON, 2002), um panorama da pesquisa sobre a produção de documentários que incentivem o protagonismo e autoria dos alunos. Acredita-se que este mapeamento é oportuno, pois tais práticas audiovisuais são cada vez mais relevantes nos contextos de letramento multissemióticos e multimidiáticos (ROJO, 2009), nas relações pessoais mediadas por tecnologias (JENKINS, 2009; SANTAELLA, 2013, 2014) e, principalmente, por possibilitarem, ao longo do processo de produção, um conhecimento reflexivo que favorece o desenvolvimento da autonomia dos alunos (FREIRE, 2011), além de estarem em consonância com as atuais políticas educacionais do Ministério da Educação presentes na Base Nacional Comum Currículo (BNCC).

A BNCC de 2018 apresenta em seu texto inicial o conceito de competência: "a mobilização de conhecimentos (conceitos e procedimentos), habilidades (práticas, cognitivas e socioemocionais), atitudes evalores para resolver demandas complexas da vida cotidiana, do pleno exercício da cidadania e do mundo do trabalho" (BRASIL, 2018. p. 8). Ao definir esse conjunto que norteará toda a educação básica, o documento apresenta uma visão mais humana e alinhada com as demandas atuais da sociedade. A partir dessa visão, é possível inferir que a proposta de produção de documentários autorais no espaço da escola dialoga, em especial, com três das competências gerais da BNCC destacadas a seguir: 
1. Valorizar e utilizar os conhecimentos historicamente construídos sobre o mundo físico, social, cultural e digital para entender e explicar a realidade, continuar aprendendo e colaborar para a construção de uma sociedade justa, democrática e inclusiva. (...)

4. Utilizar diferentes linguagens - verbal (oral ou visual-motora, como Libras, e escrita), corporal, visual, sonora e digital -, bem como conhecimentos das linguagens artística, matemática e científica, para se expressar e partilhar informações, experiências, ideias e sentimentos em diferentes contextos e produzir sentidos que levem ao entendimento mútuo.

5. Compreender, utilizar e criar tecnologias digitais de informação e comunicação de forma crítica, significativa, reflexiva e ética nas diversas práticas sociais (incluindo as escolares) para se comunicar, acessar e disseminar informações, produzir conhecimentos, resolver problemas e exercer protagonismo e autoria na vida pessoal e coletiva (BRASIL, 2018, p. 9).

A competência geral 1 menciona a ideia de "entender e explicar a realidade". Esse conceito vai ao encontro da célebre definição de documentário dada por John Grierson 1: "documentário é o tratamento criativo da realidade" (NICHOLS, 2005, p. 51) Partindo dessas definições, é possível dizer que a produção documental pode fornecer ao aluno um instrumento para pensar a sua realidade de maneira crítica, fazendo-o significar o espaço em que vive e convive e também suas relações. Ao fazê-lo, potencialmente pode-se pensar em como se inserir e construir esse conjunto de maneira mais justa, democrática e inclusiva. Outro desafio pedagógico que a produção audiovisual traz para o campo da educação é que, segundo Nichols, o documentário traz consigo um conceito de experimentação constante, que move os documentaristas a sempre buscarem novas abordagens para retratar o real:

\begin{abstract}
Os documentários não adotam um conjunto fixo de técnicas, não tratam de apenas um conjunto de questões, não apresentam apenas um conjunto de formas ou estilos. Nem todos os documentários exibem um conjunto único de características comuns. A prática do documentário é uma arena onde as coisas mudam. Abordagens alternativas são constantemente testadas e, em seguida, adotadas por outros cineastas ou abandonadas. Existe contestação. Sobressaem-se obras prototípicas, que outras emulam sem jamais serem capazes de copiar ou imitar completamente. Aparecem casos exemplares, que desafiam as convenções e definem os limites da prática do documentário. Eles expandem e, às vezes, alteram esses limites (NICHOLS, 2005, p. 49).
\end{abstract}

Outros conceitos apontados na competência 4 da BNCC parecem chave para entender a importância do documentário em sala de aula no que diz respeito à forma. São eles: a) utilização da linguagem visual, sonora e digital; b) conhecimento das linguagens artísticas; c) expressar e partilhar experiências, ideias e sentimentos buscando produzir sentidos que levem ao entendimento mútuo. - Tornar um aluno apto a utilizar outras formas de linguagem para se expressar é uma necessidade

\footnotetext{
${ }^{1}$ Criador do termo "documentário" Grierson é considerado um dos principais divulgadores do gênero, foi defensor do potencial deste tipo de filme como ferramenta para a educação e cidadania, suas ideias são as bases para que o hoje conhecemos como documentários clássicos.
} 
real da escola. Um aluno letrado no atual contexto das tecnologias digitais é aquele que consegue ler, interpretar e criar, se expressar, por meio de diferentes linguagens (ROJO, 2009).

As tecnologias digitais da informação e comunicação no contexto escolar (TIDICS) já parecem responder a essa necessidade quando proporcionam ao aluno a capacidade de fazer tais leituras e experienciar os textos multimodais. Em especial, os dispositivos de captação de imagem e som possibilitam a expressão dentro do universo audiovisual, favorecendo, assim, um aprendizado significativo onde, mais do que fazer a leitura de um filme, o aluno entenda mecanismos de construção de sua narrativa na prática, uma experiência estética significativa (DEWEY, 2010), concretizando o que percebeu por suas lentes.

$\mathrm{Na}$ competência 5 a BNCC enfatiza como o uso das TIDICS nas práticas de ensino e aprendizagem devem ajudar os estudantes na sua busca por protagonismo e autoria. Mais uma vez recorremos ao documentário como resposta para esse ponto, pois nas produções documentais contemporâneas (PENAFRIA, 1999; RAMOS, 2008) verificamos como a autoria das obras tem se deslocado de uma presença onipresente e onisciente, a chamada voz de Deus (NICHOLS, 2005; LUCENA, 2012) que buscava autoritariamente convencer o público de suas ideias para a voz de autores enunciados, minorias e grupos marginalizados. Esse é o caso de iniciativas pioneiras como os Vídeos nas Aldeias ${ }^{2}$ e de produções como O Prisioneiro da Grade de Ferro (2003), de Paulo Sacramento, no qual presos utilizam câmeras digitais para contar suas próprias histórias e Elena (2012), de Petra Costa, que utiliza sua voz em offe imagens do acervo pessoal para narrar a delicada despedida da irmã. São extensos os exemplos que mostram como o autor do documentário podem expressar seu protagonismo por meio da palavra audiovisual. Essa potência levada para o ambiente escolar parece um caminho rumo à ideia do aluno autônomo e apto para pensar seu local no mundo (FREIRE, 2011).

Quanto mais o sujeito passa por experiências nas quais ele pode ser o autor de suas produções e decisões, maiores as possibilidades para o desenvolvimento de um sujeito autônomo. Dessa forma, acreditamos que na aprendizagem de determinado conteúdo, quanto mais experiência o sujeito tiver e maior for a possibilidade deste ser o autor do processo, maior será o engajamento e a construção da autonomia deste (LIMA et al., 2018, p. 4).

Integrado ao plano pedagógico da escola e de forma consciente, essa parece ser a forma lúdica para se estabelecer uma relação entre os estudantes e a sétima arte capaz, portanto, de estabelecer uma experiência concreta e próxima fundamental para entender a arte como experiência, como aponta Dewey (2010). E, ainda mesmo entre os próprios estudantes e professores, essas

\footnotetext{
2 "Precursor na produção audiovisual indígena, o Vídeo nas Aldeias dedica-se, desde 1986, à formação de cineastas indígenas e à produção e difusão de seus filmes, apoiando suas lutas e contribuindo para a garantia de seus direitos culturais e territoriais. Ao longo dessa trajetória, o VNA construiu um dos mais importantes arquivos audiovisuais sobre a realidade indígena contemporânea, reunindo cerca de oito mil horas de imagens produzidas junto a mais de quarenta povos no Brasil’. Texto de apresentação do projeto- disponível em: http://videonasaldeias.org.br/loja/sobre/. Acesso em: 11 dez. 2020.
} 
relações estéticas e interpessoais podem ganhar outros contornos, visto que uma sala de projeção se apresenta como um espaço de reflexão mais livre que as paredes da sala de aula.

Assim, as iniciativas de exibição de documentários nas sessões de cinema na escola são fundamentais para que os alunos possam conhecer os filmes, suas especificidades, os elementos de linguagem e, reconhecendo as marcas, possam se interessar pelos diversos gêneros, estilos e escolas, tal qual fazemos na literatura.

Neste sentido as sessões de cinema, conforme a lei 13.006 (BRASIL, 2014; FRESQUET; PAES, 2016) cumprem duas das principais bases da proposta triangular (BARBOSA, 2020; 2001) para o ensino de arte na escola: a apreciação artística, no sentido de favorecer a leitura multissemiótica das obras e, em segundo lugar, a contextualização histórica que pode ser realizada pelo professor orientando os alunos sobre como as condições sociais, culturais e históricas impactaram na produção ou estão representadas nos filmes. O terceiro ponto proposto por Ana Mae Barbosa seria a prática artística, ou seja, a produção, a participação ativa no processo artístico que concretiza a experiência.

Desta forma, é interessante notar que a presença do audiovisual na escola como forma de apresentação de conteúdo continua sendo importante e, na verdade, avança com os canais dos chamados "edutubers", mas na perspectiva deste artigo propõe que a produção seja parte essencial do processo de inclusão da prática audiovisual na escola, pois acredita que é ela um dos fatores de diferenciação, um passo além da apreciação estética ou do conteúdo, de modo que a realização do produto audiovisual seja construída de maneira efetiva pelos alunos.

\section{Entrar em foco}

A partir das questões elencadas anteriormente e da relevância para o debate atual no campo das tecnologias educacionais, este artigo buscou traçar um panorama de quais são as pesquisas que estão sendo desenvolvidas para dar conta desses temas. De acordo com Webster e Watson (2002) a revisão bibliográfica sistemática é essencial para aproximar áreas onde existe um acúmulo de conhecimento e descobrir campos novos de pesquisa. Pretende-se buscar o estado da arte nas pesquisas educacionais sobre a produção audiovisual de documentários por alunos com ênfase no protagonismo e autonomia dos estudantes. Para dar conta desta tarefa recorremos a duas das maiores bases de dados sobre educação, a saber: Scientific Electronic Library Online (SciELO), Portal de Periódicos da CAPES/MEC e The Education Resources Information Center (ERIC).

A pesquisa foi realizada entre outubro e novembro de 2019 e teve como descritores as seguintes palavras: 'Educação', 'Documentário' e 'Produção' e foi estabelecido como recorte um marco temporal dos trabalhos realizados nos últimos 10 anos. A partir destes, foram lidos os artigos 
apontados pelas ferramentas de busca listadas acima e selecionados em função da sua maior ou menor relevância com a questão do protagonismo e da autoria

Essa estratégia foi adotada porque, em uma pesquisa prévia, verificou-se que a delimitação da busca usando os conceitos de autoria e de protagonismo como descritores nas ferramentas de busca foi um limitador no número de resultados, ou seja, ao incluir os descritores autoria e/ou protagonismo a base foi muito pequena para o estudo, sendo este um primeiro dado relevante para observação. Acreditamos que uma possível razão seja que a definição destes conceitos é realizada normalmente de maneira mais subjetiva no corpo do texto. Desta forma buscamos, então, localizar por meio da leitura quando essa temática se assemelhava ao que julgamos coincidir com a pesquisa.

Para isso, a busca nos artigos pelas palavras "autonomia" e "protagonismo" levou em consideração o sentido freireano desses termos, ou seja, proposta que permita ao aluno experienciar o próprio aprendizado com liberdade e sendo o sujeito construtor de seu conhecimento "A autonomia, enquanto amadurecimento do ser para si, é processo, é vir a ser. (...) Uma pedagogia da autonomia tem de estar centrada em experiências estimuladoras da decisão e de responsabilidade, vale dizer, em experiências respeitosas da liberdade" (FREIRE, 2011, p. 67).

A primeira fonte foi a plataforma SciELO, uma biblioteca eletrônica que abrange uma coleção selecionada de periódicos científicos brasileiros e internacionais, em especial latino americano. A plataforma foi a que menos apresentou resultados na configuração acima: onze entradas no total. Dessas entradas, sete eram de artigos publicados no Brasil, dois na Colômbia, um na Venezuela e outro no México. Abaixo alguns achados desta pesquisa

1. Educação ambiental e cultura: articulando mídia e conhecimento popular sobre plantas (GUIDO et al., 2013): Trata da produção do documentário Causos do Cerrado (2010) sobre o conhecimento popular das plantas do cerrado. A pesquisa envolveu 20 alunos, entre 12 e 14 anos, de duas comunidades estudadas; uma professora e a diretora de uma das escolas e membros da comunidade identificados como conhecedores de plantas;

2. Relações com o saber na atividade de produção de documentário científico no ensino de biologia, cinema e educação ambiental no Parque Nacional da Restinga de Jurubatiba: reflexões e práticas interdisciplinares e transversais (FUENTES et al., 2016): Apresenta o trabalho coletivo das oficinas do curso de cinema ambiental, com alunos da graduação em biologia e pós-graduação em ciências ambientais e o retrato documental de histórias de vidas de pessoas ligadas a Restinga de Jurubatiba; 


\section{A escuta de jovens em filmes de pesquisa, artigo da Revista Educação Realidade} (BRENNER; CARRANO, 2014): Apresenta os trajetos para a realização de dois filmes de pesquisa. Realizado pelo grupo de pesquisa Observatório Jovem, graduando e mestrandos da Universidade Federal Fluminense (UFF), que tem como tema a juventude e as culturas populares negras. Descreve o processo de imersão e troca entre os membros dos grupos nas comunidades retratadas (Comunidade quilombola Santa Rita do Bracuí e de jovens da favela de Niterói-RJ). Como destaque, o artigo apresenta o conceito de filme de pesquisa:

\footnotetext{
Filme de pesquisa sintetiza as problemáticas de investigação na forma de imagens e sons documentais roteirizados e com edição. Temos percebido que este trabalho permite um modo mais direto e simples de comunicar os resultados da investigação para diferentes públicos e facilita a criação de campo de reflexividade entre pesquisadores e pesquisados. O documentário passa a ser, então, simultaneamente, meio de observação, de documentação, de provocação e possibilidade de aumento dos níveis de reflexão de todos os envolvidos no processo de investigação (BRENNER; CARRANO, 2014, p. 443).
}

De forma resumida, é possível perceber que os trabalhos que tratam da produção de documentários relacionados a conteúdos de educação ambiental e biologia utilizam o meio audiovisual, em especial o documentário, como parte de suas metodologias para mobilização de professores, alunos e demais envolvidos no processo e justificam essas escolhas pela possibilidade que o vídeo oferece de uma interação entre o assunto retratado e os produtores do conteúdo, ao mesmo tempo em que deixa marcas de autoria no produto final sendo, portanto, uma fonte de dados qualitativos sobre quem participou e quem realizou a pesquisa. Cabe destacar que em seus textos os autores reforçam o papel da subjetividade, da narração e protagonismo, ou seja, mesmo em um campo onde historicamente se construiu um imaginário da isenção e objetividade, como o das Ciências Naturais, mesmo quando lançam mão do gênero nos documentários de natureza da televisão, a linguagem escolhida pelos pesquisadores já contempla discussões éticas e estéticas sobre a forma da obra.

Na plataforma ERIC, foram utilizados os mesmos descritores traduzidos para o inglês: Education, Documentary and Video Production. A busca também foi por artigos publicados nos últimos 10 anos (2009-2019) e revisados por pares. Obteve-se o retorno de dezesseis entradas. Destes resultados, a partir da leitura dos textos, foram selecionados os artigos a seguir, que trazem cruzamentos e intersecções relevantes com os descritores e outras questões postas neste artigo: autoria e protagonismo.

\section{Rural media literacy: youth documentary videomaking as a rural literacy practice}

(PYLES, 2016): Traz uma análise dos documentários produzidos pela juventude rural da região de Appalachia na Virgínia, Estados Unidos. A autora, a partir de métodos de análise de imagem e som 
do documentário, defende o conceito de letramento midiático rural (rural media literacy) apontando as particularidades dos valores, expressões e pessoas da área rural e como essas diferenças podem ser percebidas nas entrevistas, no discurso e na autoria das obras;

2. Lights, camera, action: advancing learning, research, and program evaluation through vídeo production in educational, leadership preparation (FRIEND; MILITELLO, 2015): No contexto da Web 2.0, o artigo elenca diversas formas de utilização do vídeo como ferramenta pedagógica, situações práticas e seu contexto, tais como: simulação de entrevistas de televisão para candidatos ao doutorado e criação de portfólios em vídeo para professores de língua inglesa. No âmbito desta pesquisa a atividade de criação de narrativas digitais com pré-adolescentes que proporcionem a noção de autoria e de experiência social pareceu alinhada com a proposta desse artigo;

\section{Digital storytelling "has great potential as an innovative and progressive way of} learning inside school ... [giving] students the opportunity to make self-representations in the school setting and foster agency" (ERSTAD; SILSETH, 2008): A pesquisa defende, ainda, que o vídeo tem potencial para ser utilizado como forma de aprendizado, pesquisa e avaliação, sugerindo que existe uma lacuna de atividades que consigam executar essas três coisas ao mesmo tempo. O trabalho aponta para a atividade de produção de documentários como uma interseção positiva entre os campos de produção e de pesquisa a partir do vídeo;

\section{Research goes to the cinema: the veracity of videography with, for and by youth} (TILLECZEK; LOEBACH, 2015): As pesquisadoras canadenses defendem que a produção videográfica pode ser um caminho para tornar os jovens mais visíveis em um contexto social que naturalmente acaba por invisibilizá-los. Para isso sugere que essa produção tenha um caráter participativo, uma videografia com, para e pela juventude "However, the use of videography with, for and by youth does open a window to a better understanding of these social contexts from this too often invisible point of view" (Ibidem, p. 355). Com esta premissa, o trabalho descreve os processos de realização de documentários com a participação de alunos com idades entre 14 e 20 anos, de comunidade de povos nativos do Canadá. Utiliza-se para isso um método de Participatory videography (Videografia Participativa [tradução do autor]. Entre os processos descritos nesta abordagem, essa metodologia propõe remover qualquer barreira tecnológica na operação do vídeo que dificulte a produção dos alunos, a existência de um espaço que favoreça sua expressão e o encorajamento dos jovens para contar suas próprias histórias. "Participatory videography is a methodology that embodies these principles by situating participants as 
filmmakers or storytellers who engage in self-research and direct the construction of their own visual productions (Evans and Foster, 2009; Lomax et al., 2011; Mistry and Berardi, 2012)" (Ibidem, p. 360).

\section{Sex, literacy and videotape: learning, identity and language eevelopment through} eocumentary production with "Overage" students (GOODMAN, 2010): O autor narra a experiência de produção de um documentário sobre o sexo na adolescência com alunos do oitavo ano, sob a perspectiva das potencialidades da prática para o ensino de língua inglesa, relacionando as competências envolvidas na pesquisa, planejamento e execução do vídeo, destacando a colaboração entre os alunos e os usos diferentes da língua (narrar, entrevistar, escrever, persuadir, resumir) na elaboração da obra;

\section{A tale of two sites: cellphones, participatory video and indigeneity in community-} based research (SCHWAB-CARTAS; MITCHELL, 2014): Apresenta alguns conceitos importantes como o participatory video research (PVR) (pesquisa participativa em vídeo) e como essa metodologia de produção de vídeo pode ser utilizada para empoderar as pessoas e ter um efeito tangível na comunidade "One of the principle aims of PVR is to use the process of media production to empower people in order to engender social change through research (...) allowing the researcher and his / her research to have a tangible effect upon the community with whom they are collaborating" (Ibidem, p. 604).

O trabalho defende que essa ferramenta não se restringe à produção audiovisual em si, mas ao processo desencadeado por ela, como forma de aumentar a confiança, habilidades e a busca de informações que impulsionam as comunidades rumo aos seus objetivos. O trabalho destaca, ainda, que essa metodologia tem sido utilizada em juventudes urbanas, mas o método PVR foi aplicado, também, em uma comunidade indígena no México e outra na África do Sul. Outro ponto importante desse trabalho é a abordagem sobre a utilização do celular, demonstrando como a ubiquidade dos aparelhos móveis é uma potência para a disseminação dos conteúdos produzidos de celularpara-celular.

8. Digital natives and digital media in the college classroom: assignment design and impacts on student learning (WATSON; PECCHIONI, 2011): Os pesquisadores da Universidade do estado da Louisiana defendem que um fator chave nesta era é a ideia de que os estudantes produzem novas mídias assim como consomem, mas alertam para o fato de que uma abordagem focada apenas no que se pode fazer com os multimeios tende a falhar. Em contrapartida, 
uma abordagem centrada no estudante, que entenda como essa tecnologia pode lhe ajudar a aprender melhor, tende a ser mais produtiva.

\footnotetext{
A key factor in assessing this need is for students of the digital era to produce new media as well as consume it. Mayer (2005) suggested that asking the question "what can we do with multimedia?" is adopting a technology-centered approach that is doomed to fail. Adopting a student-centered approach leads us to ask the question: "how can we adapt multimedia designs to help students learn more?" In essence, the question of "what can we do?" remains, but the motivation is different (WATSON; PECCHIONI, 2011, p. 308).
}

Os autores destacam como pontos positivos desse trabalho o aumento das habilidades de expressão e comunicação multimodais dos participantes; o desenvolvimento da capacidade de se comunicar por meio da linguagem audiovisual; e a colaboração entre os pares.

A plataforma Eric permitiu acesso a um banco de artigos relevante a esta pesquisa, mostrando estudos realizados na América do Norte, em especial no Canadá, bastante variados em suas metodologias e contextos de aplicação dos projetos: escolas rurais, escolas urbanas e instituições educacionais ligadas aos povos indígenas. Este panorama auxilia na compreensão de questões metodológicas e nas possíveis abordagens dos objetos, mesmo em contexto internacional. Isso indica que é plausível projetar e espelhar desdobramentos dessas metodologias em um país tão diversificado culturalmente como o Brasil.

No portal de periódicos da Capes/MEC nossa pesquisa se deparou com um total de 110 entradas de artigos. Como o portal funciona como um agregador de pesquisas de outros portais, foram excluídas as entradas da plataforma SciELO e tivemos, assim, divididos por portais, o seguinte resultado: OneFile (GALE) (89), Directory of Open Access Journals (DOAJ) (16), Materials Science \& Engineering Database (10), Advanced Technologies \& Aerospace Database (5), Library \& Information Science Collection (3) e Dialnet (1).

Apesar do número razoável de entradas, ao ler os artigos, nota-se que a maior parte foge ao escopo desta pesquisa por não apresentar nenhum tipo de atividade de produção de documentário com alunos. A leitura, entretanto, trouxe dados sobre o uso geral deste gênero de filme. Os documentários são usados como: a) material ilustrativo de algum conteúdo específico presente na obra; b) genericamente como um exemplo de prática audiovisual; c) como subsídio ou ponto de partida para um debate, sendo que, nesse caso, percebe-se que os autores selecionam títulos instigantes que ajudam a fomentar a discussão; d) como um entre os vários gêneros audiovisuais. 
Quadro 1 - Documentário e suas definições nos artigos pesquisados

\begin{tabular}{|c|c|c|}
\hline Categoria & $\begin{array}{ll}\text { Exemplo } \\
\end{array}$ & Fonte: \\
\hline $\begin{array}{l}\text { Exemplifi- } \\
\text { cando algum } \\
\text { conteúdo } \\
\text { específico da } \\
\text { obra }\end{array}$ & $\begin{array}{l}\text { "Duramente retratada no documentário Falcão, os meninos do } \\
\text { tráfico e levada ao paroxismo pelo dilaceramento do corpo de } \\
\text { um menino sendo arrastado pelas ruas do Rio de Janeiro, a } \\
\text { violência dispensa indicadores, mas, exatamente pela dimen- } \\
\text { são alcançada, exige ações, ao mesmo tempo em que teste- } \\
\text { munha a alienação dos cidadãos e a inoperância dos órgãos } \\
\text { públicos" (p. } 72 \text { ) }\end{array}$ & $\begin{array}{l}\text { SARAIVA, } \\
2008 .\end{array}$ \\
\hline Uso genérico & $\begin{array}{l}\text { "Por meio do questionário aplicado, os professores aponta- } \\
\text { ram que utilizam o vídeo para aulas expositivas, complemen- } \\
\text { tando o assunto abordado em sala, como por exemplo, um } \\
\text { documentário sobre a história de cordéis. Já a câmera é utili- } \\
\text { zada para filmagem das atividades dos alunos e posterior- } \\
\text { mente, exibição nas feiras que a escola realiza, como leitura } \\
\text { de cordéis pelos alunos" (p. 294). }\end{array}$ & $\begin{array}{l}\text { BITANTE } \\
\text { et al., } 2016 .\end{array}$ \\
\hline $\begin{array}{l}\text { Ponto de } \\
\text { partida para } \\
\text { um debate }\end{array}$ & $\begin{array}{l}\text { "Transmitimos um trecho do documentário "Criança, a } \\
\text { alma do negócio" e então o debate foi direcionado para os } \\
\text { impressionantes números sobre o consumismo infantil, como } \\
\text { por exemplo, o tempo médio que as crianças passam em } \\
\text { frente à TV e outros dispositivos eletrônicos como celulares e } \\
\text { tablets (nesse caso, } 5 \text { horas por dia); sobre comerciais volta- } \\
\text { dos exclusivamente para alimentos processados para crianças } \\
\text { com o uso de personagens de desenhos, filmes e personalida- } \\
\text { des do YouTube em suas embalagens" (p. } 210 \text { ) }\end{array}$ & $\begin{array}{l}\text { OLIVEIRA; } \\
\text { CERNY, } \\
2019 .\end{array}$ \\
\hline $\begin{array}{l}\text { Como um } \\
\text { dos gêneros } \\
\text { audiovisuais }\end{array}$ & $\begin{array}{l}\text { "No estado de São Paulo, observou-se que os telejornais } \\
(26,6 \%) \text {, reportagens }(10,6 \%) \text {, entrevistas }(1,9 \%) \text {, documen- } \\
\text { tários }(3,8 \%) \text {, auditório }(8,5 \%) \text {, telenovela }(13,1 \%) \text {, musical } \\
(1,1 \%) \text {, talk show }(4,5 \%), \text { infantil }(8,6 \%) \text {, humorístico }(2,7 \%) \text {, } \\
\text { propaganda }(2,7 \%) \text {, variedades }(11,4 \%) \text {, game show }(4,2 \%) \\
\text { são exclusivamente de produção nacional. Note-se nula a } \\
\text { produção de programas regionais no referido Estado" (p. 6- } \\
7) \text {. }\end{array}$ & $\begin{array}{l}\text { GALHARDI } \\
\text { et al., } 2017 .\end{array}$ \\
\hline
\end{tabular}

Fonte: Elaborado pelos autores.

Dos trabalhos em consonância com os objetivos do presente artigo, cabe destacar os três seguintes:

1. Produção de documentário com alunos da educação de jovens e adultos: uma proposta metodológica para elaboração de material didático includente (APARECIDA; FERREIRA, 2014): O artigo detalha a metodologia de desenvolvimento de um documentário como base de conteúdo para material didático includente (MDI) na área de química para alunos de Educação de Jovens e Adultos (EJA). A metodologia proposta no artigo parte da consideração pelos saberes e leituras de mundo dos alunos, na perspectiva freireana das autoras, para debater 
VERSUTI, Andrea Cristina; MONNERAT, Érico. O aluno em foco - um panorama sobre a produção audiovisual de documentários por estudantes em contexto escolar

sobre conceitos e questionamentos da química que os participantes vivenciam. Das entrevistas mediadas pelas pesquisadoras e da troca de experiência com os participantes surge o material que subsidiará a produção dos futuros MDI;

2. Formas de vida na imagem: da indeterminação à inconstância (BRASIL, 2010): Neste artigo, o autor problematiza a questão da representação do real em diversos meios audiovisuais, reality shows, documentários, vídeo-arte, jornalismo, questionando como a sociedade capitalista consome estas representações da vida pessoal, demanda um realismo ao mesmo tempo em que cria regras e contextos manipulados para que essas representações sejam performatizadas. "Esse apelo realista é vivido de forma nada ingênua, diríamos, reflexiva: trata-se, afinal de contas, de uma performance, de um jogo e, portanto, as experiências que ali se experienciam podem ser acompanhadas, sem maiores problemas, em sua dimensão puramente ficcional, artificial" (p. 192).

\section{Investigação de uma abordagem para o ensino de produção de narrativas digi-} tais: um estudo com foco em práticas de multiletramentos no contexto escolar público (SIQUEIRA CECCHI; REIS, 2015): As autoras trazem importantes conceitos, como o de narrativas digitais (ND), no qual se pode explorar uma variedade de linguagens (verbais, não-verbais e multimodais), destacando sua importância nas práticas de multiletramento e letramento em língua materna no contexto tecnológico atual. Diversos exemplos são dados para corroborar a tese de que se pode fazer o cruzamento entre a língua escrita e as linguagens multimodais contemplando o contexto dos alunos como potencializador das práticas de produção. As autoras enfatizam que esse é um campo novo de pesquisa e por esta razão sugerem uma pesquisa-ação resumida no gráfico da Figura 1:

Figura 1 - Abordagem Pedagógica de Ensino de Narrativa Digital - ANPED

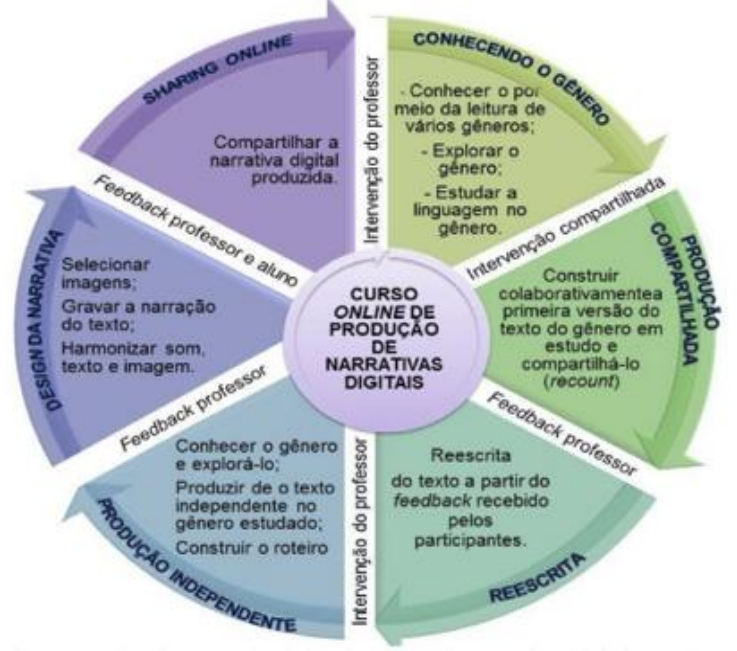

Fonte: Reis e Cecchin (2015). 
Após análise desses três bancos de dados é razoável fazer alguns apontamentos. O primeiro deles diz respeito à própria quantidade de artigos e da descrição do contexto onde foram realizados. Embora o audiovisual como um todo seja bastante utilizado em sala de aula, e cada vez mais presente, pela portabilidade das câmeras, as produções científicas sobre o gênero documentário na educação tratado sob o recorte proposto nesse artigo, ou seja, como o gênero seria o cerne do trabalho realizado com alunos e professores em uma escola, primando pela autoria e protagonismo, ainda parecem explorar de modo secundário a questão, principalmente nas escolas brasileiras. Esta percepção advém dos resultados comparativos encontrados na plataforma internacional ERIC que, diferente das pesquisas nacionais, traz relatos de experiências com metodologias mais descritivas e aprofundadas e, aparentemente, mais integrados às escolas e aos contextos dos alunos, ou seja, que tendem a resultados mais significativos.

A partir de outros dados recorrentes nesta revisão podemos perceber que mesmo em diferentes contextos, objetos e metodologias aplicadas, alguns pontos parecem ecoar nos projetos: a) a perspectiva da experiência dos alunos nos processo de realização dos vídeos, ou seja, a ênfase que as metodologias dão na importância de que os alunos tenham autonomia não só no conteúdo retratado, mas também na operação técnica e, portanto, na forma e escolhas estéticas dos documentários produzidos; b) que as questões técnicas de uso dos equipamentos em maior ou menor grau são, de certa forma, um obstáculo para realização dos projetos, porém, facilmente contornáveis pela dedicação dos alunos motivados na execução dos vídeos; c) uma notada despreocupação com uma abordagem de resultado final, de se ter uma obra dentro dos parâmetros do "correto" ou do belo. Nota-se, assim, que os artigos enfatizam que a caminhada é mais importante que a chegada em si.

Um dos objetivos da revisão de literatura, conforme Creswell (2010), é o de verificar as possíveis lacunas a serem preenchidas nos campos de pesquisa. Neste sentido o panorama que pudemos traçar foi muito útil para pensar a produção de novas pesquisas e artigos. O resultado indica que a produção de documentários autorais, que coloquem a autoria e o protagonismo do aluno como elemento central do estudo e que o faça a partir de uma gênero audiovisual específico, o documentário, ainda pode ser mais explorado pela sua relevância pedagógica, cultural e social. É uma realidade que as práticas de linguagem contemporâneas com novos gêneros e textos multimidiáticos e multissemióticos exigem que a escola se torne permeável aos conteúdos produzidos dentro e fora de seus muros. Compreender como essas formas de produção e disponibilização de vídeos, áudios, textos e fotos podem ser abarcadas ética e criticamente nas práticas pedagógicas é o desafio. 
Um outro aspecto da revisão de literatura diz respeito à própria tecnologia. Percebe-se que pelo recorte proposto, últimos 10 anos, as câmeras digitais são o principal suporte para a captação das imagens, mas os celulares são citados como interface em apenas um dos artigos. Segundo dados da Anatel (2020) a densidade média de celulares no brasil é 96 aparelhos para cada 100 habitantes. Segundo o relatório do Cetic.br (2019) sobre pesquisa acerca do uso das Tecnologias de Informação e Comunicação nas Escolas Brasileiras (TIC Educação 2018) 57\% dos alunos que responderam ao questionário disseram ter participado de alguma atividade colaborativa de produção de música, vídeo, ou jogo usando computador e internet. Como aponta a mesma pesquisa no Brasil, em geral, os alunos ainda têm limitações para o uso do telefone celular nos espaços escolares, mas já existe na pesquisa um indicador de que 55\% dos alunos utilizaram o aparelho para atividades escolares, o que pode indicar uma mudança de comportamento.

Como aponta Machado (1999, p. 10) "Aparelhos, processos e suportes possibilitados pelas novas tecnologias repercutem, como bem sabemos, em nossos sistemas de vida e de pensamento, em nossa capacidade imaginativa e nas nossas formas de percepção do mundo". Desta forma é possível imaginar que com o avanço desses números e uma presença maior dos aparelhos móveis, é possível que o contexto de produção e das práticas pedagógicas com audiovisual tenha um novo patamar. A presença das câmeras nos smartphones pode ser catalisador no processo de captura, manipulação de imagens e som, e as próximas pesquisas com produção audiovisual precisam levar essa realidade em conta.

\section{Referências:}

APARECIDA, S. C.; FERREIRA, D. C. K. Produção de documentário com alunos da educação de jovens e adultos: uma proposta metodológica para elaboração de material didático includente. Tecné Episteme y Didaxis: TED, Bogotá, n. extraordinário, p. 609-619, 2014.

ANATEL, Agência nacional de Telecomunicações. Painéis de dado telefonia móvel. 2020. Disponível em: https://www.anatel.gov.br/paineis/acessos/telefonia-movel. Acesso em: 18 mar. 2020.

BACICH, L.; MORAN, J. (Orgs.). Metodologias ativas para uma educação inovadora: uma abordagem teórico-prática. Porto Alegre: Penso, 2018.

BARBOSA, A. M. John Dewey e o ensino da arte no Brasil. São Paulo: Cortez, 2001.

BARBOSA, A. M. A imagem no ensino da arte. [S.l.]: Editora Perspectiva SA, 2020.

BITANTE, A. P; FARIA, A. C.; GASPAR, M. A.; PASCUAL, J. V. I.; CONAIRE, D. Impactos da tecnologia da informação e comunicação na aprendizagem dos alunos em escolas públicas de São Caetano do Sul (SP). HOLOS, v. 8, p. 281-302, 2016.

BRASIL, A. Formas de vida na imagem: da indeterminação à inconstância. Revista Famecos: mídia, cultura e tecnologia, v. 17, n. 3, p. 190-198, 2010. 
BRASIL. Base Nacional Comum Curricular 2018. Brasilia: MEC. Disponível em: http:/ /basenacionalcomum.mec.gov.br/images/BNCC_EI_EF_110518_versaofinal_site.pdf. Acesso em: 22 out. 2019.

BRASIL. Lei $n^{\circ} 13.006$, de 26 de junho de 2014. Acrescenta $\int 8^{\circ}$ ao art. 26 da Lei no 9.394, de 20 de dezembro de 1996, que estabelece as diretrizes e bases da educação nacional, para obrigar a exibição de filmes de produção nacional nas escolas de educação básica. Diário Oficial [da] República Federativa do Brasil, Poder Executivo, Brasília, DF, 27 jun. 2014.

BRENNER, A. K.; CARRANO, P. C. R. Os sentidos da presença dos jovens no ensino médio: representações da escola três filmes de estudantes. Educação \& Sociedade, v. 35, n. 129, p. 1223 1240, 2014.

Cetic.br. TIC Educação - 2018. 2019. Disponível em: https://cetic.br/pesquisa/educacao/indicadores/. Acesso em: 29 maio 2021.

CRESWELL, J. W. Projeto de pesquisa métodos qualitativo, quantitativo e misto. In:

CRESWELL, J. W.; CLARK, V. L. P. Pesquisa de métodos mistos. Tradução: Magda Lopes. 3. ed. Porto Alegre: Bookman. 2010. p. 207-236.

DEWEY, J. Arte como experiência. Tradução: Vera Ribeiro. São Paulo: Martins Fontes, 2010.

ERSTAD, O; SILSETH, K. Agency in digital storytelling: challenging the educational context. In: LUNDBY, D. (Ed.). Digital storytelling, mediatized stories: self-representations in new media. New York: Peter Lang, 2008, p. 213-232.

FREIRE, P. Pedagogia da autonomia: saberes necessários à prática educativa. 43. ed. São Paulo: Paz e Terra, 2011.

FRESQUET, A. M.; PAES, B. T. A escola e o cinema: algumas reflexões e apreensões frente à lei 13.006/14. Revista Teias, [S.1.], v. 17, n. 44, p. 163-172, fev. 2016.

FRIEND, J.; MILITELLO, M. Lights, camera, action: advancing learning, research, and program evaluation through video production in educational leadership preparation. Journal of Research on Leadership Education, v. 10, n. 2, p. 81-103, 2015.

FUENTES, N. M. M.; COSTA, R. N.; RUTA, C. Cinema e educação ambiental no Parque Nacional da Restinga de Jurubatiba: reflexões e práticas interdisciplinares e transversais. Educaşão e Sociedade, v. 136, p. 1-19, 2016.

GALHARDI, C. P.; ORTEGA, F.; IGARTUA, J. J. A TV de Silvio Santos-estratégias mercadológicas na grade de programação do SBT: um enfoque quantitativo. Revista FAMECOS: mídia, cultura e tecnologia, v. 24, n. 1, 2017.

GOODMAN, S.; Sex, literacy and videotape: learning, identity and language development through documentary production with "Overage" students. English Teaching: Practice and Critique, v. 9, n. 1, p. 48-57, 2010. 
GUIDO, L. F. E.; DIAS, I. R.; FERREIRA, G. L.; MIRANDA, A. B. Educação ambiental e cultura: articulando mídia e conhecimento popular sobre plantas. Trabalho, Educação e Saúde, v. 11, n. 1, p. 129-144, 2013.

JENKINS, H. Cultura da convergência: a colisão entre os velhos e novos meios de comunicação. Tradução: Susana Alexandria. 2a ed. São Paulo: Aleph, 2009.

LIMA, D. J.; MERCADO, L. P. L.; VERSUTI, A. C. Transmidiação e educação. In: VERSUTI, A. C.; SANTOS, G. L. (Orgs.). Educaşão, tecnologias e comunicação. Brasília: Viva Editora, 2018.

LUCENA, L. C. Como faz̧er documentários: conceito, linguagem e prática de produção. [S. 1.]: Summus Editorial, 2012.

MACHADO, A. Repensando Flusser e as imagens técnicas. Revista de Comunicação e Linguagens: Real vs. Virtual, n. 25/26, p. 31-45, 1999.

NICHOLS, B. Introdução ao documentário. São Paulo: Papirus Editora, 2005.

OLIVEIRA, E. A. S.; CERNY, R. Z. Semana acadêmico do curso de pedagogia: memes em prol da infância para criticar o consumismo. Periferia, v. 11, n. 2, p. 203-219, 2019.

PENAFRIA, M. Perspectivas de desenvolvimento para o documentarismo. Portugal: Universidade da Beira Interior, 1999.

PYLES, D. G.. Rural media literacy: youth documentary videomaking as a rural literacy practice. Journal of Research in Rural Education (Online), v. 31, n. 7, p. 1, 2016.

RAMOS, F. P. Mas afinal... o que é mesmo documentário? São Paulo: Senac/SP, 2008.

ROJO, R. Letramentos múltiplos, escola e inclusão social. São Paulo: Parábola Editorial, v. 200, 2009.

SANTAELLA, L. Desafios da ubiquidade para a educação. Revista Ensino Superior Unicamp, v. 9, p. 19-28, 2013.

SANTAELLA, L. Comunicação ubiqua: repercussões na cultura e na educação. São Paulo: Editora Paulus, 2014.

SARAIVA, J. I. A. Universalização da leitura e valorização da literatura: condição para o desenvolvimento social. Acta Scientiarum. Language and Culture, v. 30, n. 1, p. 71-78, 2008.

SCHWAB-CARTAS, J; MITCHELL, C. A tale of two sites: cellphones, participatory video and indigeneity in community-based research. McGill Journal of Education/Revue des sciences de l'éducation de McGill, v. 49, n. 3, p. 603-620, 2014.

SIBILIA, P. Redes ou paredes: a escola em tempos de dispersão. Tradução: Vera Ribeiro. Rio de Janeiro: Contraponto, 2012.

SIQUEIRA CECCHIN, A.; REIS, S. C. Investigação de uma abordagem para o ensino de produção de narrativas digitais: um estudo com foco em práticas de multiletramentos no contexto escolar público. Veredas-Revista de Estudos Linguísticos, v. 20, n. 1, 2016. 
TILLECZEK, K.; LOEBACH, J. Research goes to the cinema: the veracity of videography with, for and by youth. Research in Comparative and International Education, v. 10, n. 3, p. 354-366, 2015.

WEBSTER, J.; WATSON, R. T. Analyzing the past to prepare for the future: writing a literature review. MIS Quarterly, v. 26, n. 2, p. xiii-xxiii, 2002.

WATSON, J. A.; PECCHIONI, L. L. Digital natives and digital media in the college classroom: assignment design and impacts on student learning. Educational Media International, v. 48, n. 4, p. 307-320, 2011.

\section{Referências Audiovisuais}

ELENA. Direção: Petra Costa. Elenco: Elena Andrade, Li Na e Petra Costa. Roteiro: Petra Costa, Carolina Ziskind. Brasil: Busca Vida Filmes, 2012. 1 DVD (82 min), son., color.

O PRISIONEIRO da grade de ferro: auto retratos. Direção: Paulo Sacramento. Elenco: Celso Ferreira de Albuquerque, Cláudio Fabiano, Etelvino Batista da Silva et al. São Paulo: Imovision, 2003. 1 DVD (123 min), son., color.

2016. 